\title{
DESAFIANDO AS FRONTEIRAS ENTRE SINDICATOS E MOVIMENTOS SOCIAIS EM MEIO À PANDEMIA: CAMPANHAS DE COALIZÃO EM DEFESA DO SUS NA CIDADE DE SÃO PAULO EM 2020'
}

\author{
Recebido em 3/02/2021, aprovado em 12/03/2021 \\ 10.30612/mvt.v8i14.15029 \\ Alexandre Espreafico Guelerman Ramos ${ }^{2}$
}

\begin{abstract}
RESUMO: De que modo a profunda crise sócio-reprodutiva da pandemia de COVID-19 impactou as estratégias sindicais em cada contexto político-institucional? Neste trabalho, contribuímos a essa questão analisando as estratégias de coalizão entre sindicatos de saúde e movimentos sociais na cidade de Sáo Paulo, mediante sete entrevistas semi-dirigidas realizadas com dirigentes do Sindicato dos Servidores Municipais de São Paulo (Sindsep) e lideranças de movimentos populares de saúde (atuantes também em conselhos gestores). Em Sáo Paulo, os impactos da pandemia devem ser entendidos em conexáo com uma gestão municipal (2017-2020) pouco permeável à sociedade civil e com políticas de precarização do sistema de saúde, incluindo desvalorização dos servidores públicos e terceirização das unidades de saúde (com efeitos não apenas sobre a qualidade dos serviços, mas também sobre a organizaçáo sindical). Em reação a esse contexto, sindicatos e movimentos sociais de saúde já vinham recorrendo a campanhas em coalizão antes mesmo da pandemia e, com o advento desta, buscaram mobilizar a comoção social e obtiveram êxito a nível local, apesar de importantes derrotas a nível do município. As campanhas analisadas apresentam distintos graus de "profundidade" e resultados, mas entre seus elementos importantes incluem-se, em geral: a realização de pequenos protestos e "atos relâmpago"; a combinação de comunicação através de redes sociais com a busca por chamar a atenção de veículos de imprensa; o apoio de parlamentares e de outros movimentos sociais dos bairros (em alguns casos mesmo de associaçóes sem grande trajetória reivindicativa prévia); e apelos ao Ministério Público e ao Tribunal de Contas do Município.
\end{abstract}

Palavras-chave: Sindicalismo. Coalizóes. Movimento de Saúde. Pandemia. Terceirização.

\footnotetext{
1 Esse trabalho apresenta parte dos resultados da pesquisa "Estratégias de Coalizão em São Paulo: Perspectivas Para uma Renovação Territorial do Sindicalismo", conduzida entre fevereiro e dezembro de 2020 com financiamento da Fundação de Amparo à Pesquisa do Estado de São Paulo (FAPESP), sob orientação do Prof. Dr. Ruy Gomes Braga Neto (Departamento de Sociologia da Universidade de São Paulo - USP). Número do processo: 2019/22049-8.

2 Graduado em Ciências Sociais pela Universidade de Sáo Paulo (2017-2020). Mestrando do Programa de Pós-Graduação em Sociologia da Universidade de São Paulo (2021-...). E-mail: alexandre egramos@usp.br.
} 


\title{
[CHALLENGING THE BORDERS BETWEEN LABOR UNIONS AND SOCIAL MOVEMENTS AMIDST THE PANDEMIC: CAMPAIGNS IN COALITION IN DEFENSE OF THE UNIVERSAL HEALTHCARE SYSTEM IN SÃO PAULO IN 2020]
}

\begin{abstract}
How has the deep socio-reproductive crisis of the COVID-19 pandemic impacted trade union strategies in each political institutional-context? In this article, we contribute to this question focusing on the coalition-building strategies between trade unions and social movements in the healthcare movement in Sáo Paulo. Our empirical data draws mainly from seven semi-directed interviews conducted with leaders from community healthcare movements (acting also in healthcare councils) and officers from the Union of Municipal Public Sector Workers of São Paulo (Sindsep). The pandemic crisis in São Paulo was combined with a municipal administration (2017-2020) barely permeable to civil society and with systematic politics of precarization of the healthcare system, including attacks on public-sector workers and subcontracting of healthcare units (with effects both on the quality of the service and on the trade union organisation). In reaction to these characteristics of the municipal administration, trade unions and pro-healthcare social movements had been conducting campaigns in coalition before the pandemic, and after it they tried to mobilize a social commotion by the health crisis, managing to achieve favorable results in some neighborhoods, despite important losses at the municipal level. The campaigns we studied offer distinct results and "deepness", but it can be emphasized as general important elements within them: the conduction of quick protests and performances, the communication through both social media platforms and conventional press, the support of city councilors and other neighborhood social movements (in some cases, even some without great previous claiming actuation), and appeals to the Public Ministry and the Tribunal of Municipal Budget.
\end{abstract}

Keywords: Unionism. Coalitions. Healthcare Movement. Pandemic. Subcontracting.

\section{[DESAFIANDO LAS FRONTERAS ENTRE SINDICATOS Y MOVIMIENTOS SOCIALES EN MEDIO DE UNA PANDEMIA: CAMPAÑAS DE COALICION EN DEFESA DEL SUS EN LA CIUDAD DE SÃO PAULO]}

RESUMEN: ¿Cómo ha impactado la profunda crisis socio-reproductiva de la pandemia COVID-19 las estrategias sindicales en cada contexto político-institucional? En este trabajo contribuimos a este tema analizando las estrategias de coalición entre los sindicatos de salud y los movimientos sociales en la ciudad de São Paulo, a través de siete entrevistas semidirigidas realizadas a líderes del Sindicato de Servidores Municipales de São Paulo (Sindsep) y líderes de los movimientos populares de salud (también activos en consejos de gestión de las unidades de salud). En São Paulo, los impactos de la pandemia deben entenderse en relación con una gestión municipal (2017-2020) que no es permeable a la sociedad civil y con políticas de precarización en el sistema de salud, incluida la devaluación de los servidores públicos y la subcontratación de unidades de salud (con efectos no solo en la calidad de los servicios, sino también en la organización sindical). Ante este contexto, los sindicatos y movimientos sociales de salud ya recurrían a campańas de coalición mismo antes de la pandemia, y con el advenimiento de la pandemia buscaran movilizar la conmoción social, obteniendo victorias a nivel local a pesar de importantes derrotas en el municipio. Las campańas analizadas presentan distintos grados de "profundidad" y resultados, pero entre sus elementos importantes se incluyen, en general: la realización de pequeñas protestas y "actos relámpago"; la combinación de 
la comunicación a través de las redes sociales y la búsqueda para llamar la atención de la prensa; el apoyo de parlamentarios y otros movimientos sociales de los barrios (en algunos casos incluso de asociaciones sin una gran trayectoria reivindicativa previa); y recursos ante el Ministerio Público y el Tribunal de Cuentas Municipal.

Palavras Clave: Unionismo. Coaliciones. Movimiento de Salud. Pandemia. Tercerización.

\section{INTRODUÇÃO E OBJETIVOS}

A pandemia gerou uma crise de proporçóes extraordinárias na estrutura econômica e social. Os gestores de políticas públicas se viram perante desafios até então inéditos, no que se refere à adequação dos serviços públicos e das políticas de proteção social, tema que abre importante campo de reflexão acadêmica; igualmente, atenção tem sido despendida acerca das estratégias empresariais de adaptação a esse período e dos efeitos macroeconômicos do vírus. Mas outro tema de grande importância diz respeito aos impactos da crise sanitária na dinâmica da sociedade civil: como o isolamento social abalou os procedimentos tradicionais de comunicação, organização e mobilização dos sindicatos e movimentos sociais? Como a pandemia impactou as estratégias das lideranças organizacionais desses movimentos? Quais novas pautas foram, em cada movimento, acentuadas com a crise sanitária e social?

Trata-se de um amplo campo de investigação que excede em muito o escopo desse artigo. No entanto, certamente são questôes que se insinuaram a todos os pesquisadores que se dedicaram, no atípico ano de 2020, a estudos empíricos acerca de sindicatos e movimentos sociais. Em nosso caso, conduzimos entre fevereiro e dezembro de 2020 uma pesquisa de Iniciação Científica, financiada pela Fundação de Amparo à Pesquisa do Estado de São Paulo (FAPESP), acerca de estratégias de coalizão entre sindicatos e movimentos sociais urbanos na cidade de São Paulo, na qual o tema da pandemia não figurava no projeto original, mas perpassou os resultados obtidos. Nosso objetivo principal nessa pesquisa era avaliar, a partir de um conjunto de casos empíricos concentrados no movimento de saúde e no movimento de mobilidade urbana, quais variáveis poderiam explicar a diversidade de investimento em estratégias de coalizão, tipos de recursos despendidos nessas campanhas e resultados e avaliaçóes de dirigentes sindicais e de movimentos sociais.

Nesse artigo, gostaríamos de discutir especificamente os nossos estudos de caso referentes ao movimento de saúde, entendido como aquele formado por movimentos populares de saúde dos distritos da cidade e sindicatos com representação entre trabalhadores do setor. Discutiremos, sobretudo, os efeitos da pandemia nas características das campanhas analisadas. Esses efeitos, por sua vez, só podem ser explicados mediante uma contextualização acerca do projeto político da gestão municipal tucana de 2016-2020, de baixa permeabilidade à sociedade civil, intensa subcontratação das unidades de saúde, desvalorização do quadro de servidores e precarização do sistema de saúde. Além disso, é necessária uma prévia contextualização acerca dos sindicatos de saúde atuantes na cidade e a forma como suas estruturas têm sido impactadas pelas transformaçôes na administração da rede de atendimento básico e hospitalar, bem como dos movimentos de saúde atuantes na cidade e sua relação com a legislação de participação popular no município. Por fim, para analisar os efeitos da pandemia sobre as campanhas é necessário enfatizar também a agência dos referidos movimentos, isto é, os recursos e repertórios de ação que esses sindicatos e movimentos sociais buscaram mobilizar nas referidas campanhas, valendo-se de tradiçôes de associativismo locais e apelando à maior comoção social gerada pela pandemia. 
Abordando estratégias de coalizão entre sindicatos e movimentos sociais em um contexto de crise de reprodução social, esse trabalho se relaciona diretamente ao tema deste Dossiê. Desafiando as fronteiras entre os locais de trabalho e as comunidades nas quais eles se inserem espacial e funcionalmente, essas coalizóes apresentam grande potencial de enfrentamento à lógica ao mesmo tempo exploradora e espoliadora do neoliberalismo (BRAGA, 2017). Tal potencial é particularmente acentuado para o sindicalismo de serviços públicos e particularmente importante em um contexto de aguda crise econômica e sanitária.

Além dessa seção introdutória, esse texto tem quatro seções. Na primeira destas, introduziremos discussóes teóricas relevantes, referentes à literatura sobre revitalização sindical e estratégias de coalizão. Em seguida, sumarizaremos brevemente a metodologia de que se valeu este trabalho e as posiçôes ocupadas pelos entrevistados. Procederemos então para a contextualização, apresentação e discussão dos casos estudados. O texto se encerra com uma breve seção de conclusão.

\section{LUTAS EM COALIZÃO: REVISÃO BIBLIOGRÁFICA}

$\mathrm{O}$ último quartel do século $\mathrm{XX}$ assistiu a um largo conjunto de transformaçôes macrossociais que geraram extenso debate quanto a suas implicaçôes para o movimento sindical. Se, como observa Silver (2005 [2003]), é difícil postular uma unívoca, homogênea e inevitável crise global do sindicalismo, não há como negar que desde meados da década de 1970 houve uma deterioração profunda do sindicalismo no Norte Global e muitos dos elementos que acompanharam seu declínio nessa regiáo do mundo se fizeram presentes também no Sul, impactando também as formas - muito menos consolidadas - de associativismo trabalhista nesse hemisfério. $\mathrm{O}$ aumento da desigualdade social e a informalização do trabalho foram, nesse sentido, tendências notáveis no Norte e também no Sul globais, à medida que mesmo os "compromissos de classe" desenvolvimentistas do Sul, mais precários que os do Norte, também colapsaram (BREMAN, HARRIS, LEE e LINDEN, 2019). Entre as reestruturações econômicas que colocam desafios perante a atuação sindical, Silver (2005 [2003]) elenca as soluçóes "espaciais" (deslocamento do capital para novas regiôes), "de produto" (expansão para novos ramos de produtos), "tecnológica" (introduçáo de tecnologias poupadoras de trabalho, toyotismo, subcontratação) e "financeira" (deslocamento do setor produtivo para ganhos puramente rentistas) encontradas pelo capital para fazer frente a processos de agitaçáo trabalhista, aliadas aos processos diretamente políticos de cooptação e repressão.

Nesse contexto, muitos autores se voltaram a estudar teórica e empiricamente um conjunto de estratégias de que sindicatos podiam se valer para reverter a correlação de forças desfavorável, no que se conformou uma abordagem em torno das "estratégias de revitalização sindical" (IBSEN e TAPIA, 2017). Segundo Frege e Kelly (2003), pioneiros desse modelo, seis estratégias de revitalização sindical estariam se destacando no âmbito do sindicalismo europeu: i) estratégias de organizing (campanhas massivas de recrutamento nos locais de trabalho não-organizados); ii) estratégias de reestruturaçâo organizacional (fusóes, reorganizaçóes do funcionamento interno); iii) estratégias de construçâo de coalizóes com outros movimentos sociais; iv) estratégias de parceria social com Estado e empregadores; v) estratégias de ação política (lançando candidatos, apoiando políticos e partidos, fazendo protestos políticos); e vi) estratégias de conexóes internacionais.

No ano seguinte à publicação deste artigo, ele passou a integrar a coletânea Varieties of Unionism: Strategies for Union Revitalization in a Globalizing Economy, editada pelos dois autores, contando com contribuiçóes de diversos outros estudiosos empregando e aprofundando essa abordagem teórica. Gostaríamos de enfatizar, nesse sentido, o artigo de Frege, Heery e Turner (2004), que trata especificamente das estratégias de coalizão. Segundo esses autores, as estratégias de coalizão podem 
ser meramente métodos secundários para os sindicatos perseguirem seus objetivos "clássicos" de regulação das relaçóes de trabalho, ou podem ser entendidos como métodos voltados para uma função social mais ampla do sindicalismo. A definição mais geral dessas estratégias seria "atividades conjuntas discretas, intermitentes ou contínuas em busca de objetivos comuns entre sindicatos e outras instituiçóes não-trabalhistas da sociedade civil, incluindo organizaçóes atuantes em torno de comunidade, fé, identidade, advocacy, bem-estar" (FREGE, HEERY e TURNER, 2004, p. 138, tradução própria). Essa definição ressalta a cooperação formal entre organizaçóes, e afirma que os recursos de poder que sindicatos podem acessar a partir dessas formas "atípicas" de cooperação são: acesso a recursos materiais e financeiros, possibilidade de acessar setores sociais (ex.: étnicos) que o sindicato deseja organizar, ganho de expertise, ganho de legitimidade junto a determinados setores sociais e produção de mobilizaçóes de apoio a suas pautas.

Esses autores avançam ainda a uma tipologia dessas coalizões, essenciais para explicar as características e desenrolar dessas coalizóes. Segundo Frege, Heery e Turner (2004) as coalizóes entre sindicatos e movimentos sociais podem se diferenciar em função de duração, identidade, objetivos, métodos (em que podem ser mais voltadas para a "influência" dos atores governamentais ou mais voltadas para o protesto político) e graus de sucesso. Além disso, eles propóem uma tipologia das coalizóes em função de quais são os interesses que predominam nelas, e das consequências disto para a forma como são tomadas as deliberaçôes. Nas "coalizôes de vanguarda", movimentos sociais coligam-se aos sindicatos a partir de solidariedade incondicional à causa destes últimos, raramente havendo, portanto, partilha de prerrogativas de deliberação. Outras são "coalizões de causa comum", produzidas por alinhamentos de interesse entre organizaçóes provenientes de distintos âmbitos; estas frequentemente envolvem a formação de umbrella organizations, por exemplo, frentes de atuação. Esse tipo de coalizão pode se enfraquecer ou se fortalecer em função dos impactos de forças externas sobre o alinhamento de interesses (prejudicando esse alinhamento ou reforçando-o). Por fim, a terceira possibilidade é de "coalizóes integrativas", em que sindicatos oferecem apoio incondicional à causa de outros movimentos sociais, visando fortalecer o apoio de determinado setor social ou ganhar o apoio de suas próprias bases que apoiam os referidos movimentos. Geralmente os sindicatos se envolvem mais nesse tipo de coalizão na medida inversa do grau de recursos que terâo de despender nela e, por isso, muitas vezes se envolvem mais nesse tipo de coalizão a nível nacional (onde o compromisso é mais "frouxo") do que local (FREGE, HEERY e TURNER, 2004).

Outra proposta de tipologia é apresentada por Tattersall (2013), em função da profundidade da aliança. A autora argumenta que podem haver "coalizóes ad hoc" (coalizôes episódicas, frutos de pedidos de assistência por uma das partes para uma determinada iniciativa). "Coalizóes de apoio" seriam também de curto prazo, mas "estruturadas": "transformam a coalizão ad hoc 'temporária’ em um espaço formal de reunião como locus para planejamento de eventos e campanhas" (TATTERSALL, 2013, p. 100). "Coalizóes de apoio mútuo" seriam variaçóes do caso anterior, em que há uma comunhão de interesses diretos entre as organizaçóes e por isso elas seriam de um nível de estruturação e engajamento mais profundo. Por fim, o último nível seria o das "coalizóes profundas": para além da amplitude de organizaçôes e causas envolvidas, as coalizóes "profundas" se caracterizam por uma estrutura organizativa mais complexa e composta por uma variedade de escalas, de modo a produzir um engajamento de base mais intenso. Segundo a autora, ainda, essas coalizôes envolvem uma mudança na organização interna dos sindicatos de modo a valorizar a participação, a democracia interna e o engajamento (TATTERSALL, 2013). Tattersall (2006) denomina esse conjunto de estratégias community unionism, por envolver uma aproximação dos sindicatos quanto a comunidades externas aos locais de trabalho, compreendidas por três acepçóes do termo "comunidade": enquanto grupo pautado por interesses/identidades comuns; enquanto local; e enquanto organizaçôes presentes nas comunidades. 
Claramente, embora as coalizóes sejam fontes de recursos importantes, nem todas as coalizóes são duráveis ou apresentam sucesso. Certamente uma série de variáveis exógenas

podem influenciar nas possibilidades de sucesso de estratégias de coalizão. Ao mesmo tempo, muitas das dificuldades dessa estratégia no médio e longo prazo podem ser explicadas se recorrendo à tipologia de Tattersall (2013), no sentido de que muitas vezes os sindicatos não se dispóem a construir coalizões senão a nível "superficial". Segundo McAlevey (2016), por exemplo, mesmo muitos dos sindicatos que recorriam internamente a métodos de organizing profundos e procuravam outras organizaçôes para fazer coalizôes, muitas vezes apenas se associavam de forma superficial a organizaçôes pouco enraizadas, ou seja, não aplicavam nessas coalizóes a mesma concepçáo de organizing profundo que aplicavam "para dentro". Segundo Tattersall (2006), ainda, a eficácia de estratégias de coalizão não deve ser avaliada apenas com base em resultados específicos de curto prazo, mas em seus efeitos de longo prazo em termos de produção de politização e aprofundamento das relaçóes de confiança e interdependência entre as organizaçôes sindicais e as organizaçôes da comunidade.

Nos marcos dessas discussóes teóricas e conceituais, refletiremos acerca da dinâmica de coalizôes sindicais construídas no contexto da pandemia e de um governo municipal pouco permeável às demandas da sociedade civil (gestóes do PSDB de João Dória, 2017- 2018, e Bruno Covas, 2018-2020). Na conclusão, sinalizaremos também para algumas perspectivas mais gerais.

\section{METODOLOGIA}

Esse trabalho se utilizou de dois recursos metodológicos: a entrevista semi-dirigida e, subsidiariamente, análise de mídias digitais (redes sociais e publicaçôes na mídia sindical ou convencional). A respeito do primeiro, foram conduzidas sete entrevistas semi-dirigidas: três com dirigentes sindicais do Sindsep (uma jovem dirigente de base da região do Campo Limpo, o diretor de Política Intersindical e Solidariedade do sindicato e a responsável pela pasta de saúde do sindicato) e quatro com lideranças do movimento popular de saúde das seguintes regióes: Butantá/Rio Pequeno, Brasilândia/Freguesia do Ó, e adjacências da Estrada do M’boi Mirim (Campo Limpo, Jardim São Luís, Jardim Ângela). Essas entrevistas foram realizadas entre 21/08/2020 e 04/01/2021.

A opção pelo método da entrevista semi-dirigida se relaciona ao fato desta possibilitar uma estruturação da entrevista a partir de alguns eixos derivados do problema de pesquisa, mas deixando também aberta a possibilidade de renovar essas problemáticas e a própria forma de interlocução a partir dos elementos trazidos pelo interlocutor de pesquisa; nos termos de Bourdieu (1993 [2001], p. 695) esse método possibilita uma "postura de escuta

ativa e metódica”, oposta tanto ao "dirigismo do questionário" quanto à "pura não intervenção" da entrevista não dirigida. Já a análise de mídias digitais se relacionou sobretudo à busca por precisar determinados detalhes que eventualmente não fossem recordados pelos entrevistados, como datas, bem como para complementar as informaçóes apresentadas ao longo da entrevista.

\section{CONTEXTUALIZAÇÃO, APRESENTAÇÃO E DISCUSSÃO DOS RESULTADOS}

\section{PARTICIPAÇÃO POPULAR NO SISTEMA PÚBLICO MUNICIPAL DE SAÚDE}

O sistema público de saúde municipal em Sáo Paulo, instituído em conformidade com as orientaçôes participativas estruturantes da Constituição Federal de 1988 (CF88), compreende uma importante rede de participação e deliberação popular na gestão das políticas públicas de saúde. As primeiras experiências participativas no município foram, nesse sentido, estabelecidas na gestáo petista de Luiza Erundina (1989-1993); após um forte refluxo nas gestóes de Paulo Maluf e Celso 
Pitta, institutos participativos voltaram a ser instituídos, no caso da saúde, ao final da década de 1990, e ainda assim por indução de legislação federal (COELHO, 2020). Em 1999, na gestão de Celso Pitta (PPB, 1997-2000), o Decreto No 38.576 regulamentou a instituição do Conselho Municipal de Saúde, com importante participação de membros de entidades sindicais e movimentos populares de saúde das regiốes do município.

Em 2002, por iniciativa da gestão petista de Marta Suplicy (2001-2004), foram instituídos por sua vez pela Lei Municipal No 13.325 Conselhos Gestores de Unidades de Saúde nas unidades vinculadas ao SUS, tanto de administração direta quanto indireta, com $50 \%$ de representantes de usuários, $25 \%$ de representantes dos trabalhadores da saúde e $25 \%$ de representantes da direção da unidade respectiva. Como instância intermediária entre o Conselho Municipal de Saúde e os Conselhos Gestores de Unidades de Saúde, foram instituídos por decreto os Conselhos Gestores Distritais de Saúde, incorporados depois às Coordenadorias de Saúde das Subprefeituras na Lei Municipal No 13.716.

Dispondo os conselhos de saúde, nos termos desta última lei, de "caráter permanente e deliberativo, destinados ao planejamento, avaliação, fiscalização e controle da execução das políticas públicas e das açôes de saúde, em sua área de abrangência”, esses conselhos se destacaram como importantes âmbitos de elo entre a gestão das políticas públicas e a sociedade civil organizada. A ação estratégica de movimentos populares frequentemente se orienta à capacidade de eleger, influenciar e pressionar conselheiros e gestores desses equipamentos de saúde. Ao mesmo tempo, como também documentado em nossas entrevistas tanto por lideranças do movimento popular de saúde quanto por dirigentes sindicais da área de saúde, esses conselheiros são em muitas localidades eleitos ou cooptados por máquinas políticas clientelistas locais ligadas à subprefeitura ou por Organizações Sociais de Saúde (OSSs), tendendo assim a se tornar extensóes das subprefeituras ou das OSSs e sem dispor de real função de mobilização e fomento à participação popular.

Além disso, as prerrogativas deliberativas dessa rede de institutos participativos se encontram subordinadas a definiçôes mais gerais acerca de orçamento, regime de administração das unidades e carreiras dos servidores públicos, que são definidos pela prefeitura e pela Câmara dos Vereadores. Como exemplificaremos mais adiante, as gestôes municipais tucanas de João Dória (2017-2018) e Bruno Covas (2018-2020) se caracterizaram a esse respeito por baixa permeabilidade às demandas de sindicatos e movimentos sociais, com medidas prejudiciais à carreira, condiçóes de trabalho e remuneração de servidores públicos, e com uma intensificação de processos de subcontratação. Além disso, foi uma gestão que reduziu a proporção da aplicação de impostos e transferências em açóes e serviços de saúde, e levou a significativo aumento do tempo de espera para exames de especialidades (GOMES, 2020).

\section{O MOVIMENTO SINDICAL DE SAÚDE EM SÃO PAULO}

No que se refere ao movimento sindical de saúde, há uma divisão entre a rede de contratação direta, por um lado, e a rede terceirizada, por outro. Nesta última, de trabalhadores celetistas, há uma divisão de sindicatos por função, correspondendo às mesmas representaçôes dos trabalhadores da iniciativa privada: o Sindicato dos Médicos de São Paulo (SIMESP), filiado à Central Única dos Trabalhadores (CUT); o Sindicato dos Enfermeiros do Estado de São Paulo (SEESP), também filiado à CUT; o Sindicato dos Auxiliares e Técnicos de Enfermagem e dos Trabalhadores em Estabelecimentos de Serviços de Saúde de São Paulo (SinSaudeSP), filiado à Força Sindical; etc. Já no que se refere aos trabalhadores de contratação direta há, como se sabe, disputas de circunscrição, dada a não extensão das regras sindicais celetistas para esse setor, mas o Sindicato dos Servidores 
Municipais (Sindsep), ligado à CUT, é um dos mais importantes nessa representação, embora também atue em outros setores, sobretudo o educacional. O SIMESP e o SEESP também têm algumas representaçôes entre médicos do setor público, embora suas convençôes coletivas abarquem apenas os médicos do setor privado. Os servidores públicos da saúde não dispóem de mecanismos de convenção coletiva aos moldes da iniciativa privada, mas a Secretaria Municipal de Saúde dispóe de uma Mesa Permanente de Negociação com presença de todos os sindicatos com representaçáo entre os servidores públicos.

A terceirização das unidades de saúde do município, já muito avançada na rede básica e avançando na rede hospitalar, desorganiza a atuaçáo sindical em dois sentidos: primeiro, por desarticular a circunscrição tradicional de representação dos sindicatos de servidores públicos, fragmentando os trabalhadores entre vários sindicatos celetistas (no caso do Sindsep, isso tem se refletido em crescentes discussóes de começar a representar, informalmente, trabalhadores das OSSs); em segundo lugar, por, afastando a estabilidade empregatícia, aumentar os riscos envolvidos na agitação trabalhista desse setor, e também na manutenção de uma postura independente por parte do segmento trabalhador nos conselhos gestores de unidades de saúde. A luta contra processos de terceirizaçáo é uma importante pauta do sindicalismo de servidores públicos de saúde, para a qual, como discutiremos, o apoio comunitário possui grande importância.

\section{LUTAS EM COALIZÃO NA SAÚDE: DESCRIÇÃO DOS CASOS ESTUDADOS}

Entrevistamos três lideranças do Sindsep: uma dirigente de base da região do Campo Limpo; a responsável pela pasta de saúde do sindicato; e o Secretário de Política Intersindical e Solidariedade do sindicato. Este último afirmou que as redes de alianças e colaboração do sindicato compreendem principalmente: em primeiro lugar, a federação, confederação e central sindical a que se associam; em segundo lugar, outros sindicatos de servidores públicos, aos quais se juntam em determinadas lutas comuns da categoria; e, por fim, movimentos populares de saúde, no que declara que os principais "elos" com a população são as participaçóes de dirigentes do sindicato em conselhos de saúde. Ao mesmo tempo, de forma mais vaga e indefinida menciona a existência de contatos com lideranças de movimentos de moradia e associaçóes de moradores.

O mesmo dirigente mencionou as seguintes lutas recentes como as principais do sindicato, especialmente no âmbito da saúde: em 2018 e 2019, a greve e as manifestaçôes contra o "SampaPrev" (reforma da previdência dos servidores municipais que começou a

tramitar em dezembro de 2017 e foi aprovada em dezembro de 2018, aumentando a contribuição de seguridade social desses servidores); em abril de 2019, a campanha com paralisação parcial dos trabalhadores do Sistema de Atendimento Móvel de Urgência (SAMU) contra a Portaria 190 da prefeitura que fechou e realocou de forma improvisada bases de atendimento do SAMU; campanha de assistentes de gestão de políticas públicas, agentes de apoio, e assistentes de suporte técnico das autarquias em defesa da valorização da carreira, que chegou a contar com uma greve em novembro de 2019; e, sobretudo no período da pandemia, campanhas contra terceirizaçóes da administração de unidades de saúde (processo intensificado após a aprovação, em meados de 2020, da PL 749, que extinguiu as autarquias municipais, inclusive a Autarquia Hospitalar Municipal), bem como as mobilizaçôes de servidores pela disponibilização adequada de equipamentos de proteçáo individual (EPIs) e contra a remoçáo de centenas de trabalhadores da Covisa em agosto de 2020 (Coordenadoria de Vigilância em Saúde).

A luta contra o "SampaPrev", que chegou a contar, segundo seus organizadores, com uma manifestação de mais de 100.000 pessoas em frente à Câmara dos Vereadores em março de 2018, uma 
greve de 33 dias após a aprovaçáo no começo de 2019 e atos em frente a gabinetes de vereadores, é um exemplo de uma luta costurada em grande unidade entre diversos setores do sindicalismo de servidores públicos, e que contou com a adesão de diversos militantes partidários e de movimentos sociais. Foi uma luta com importante reverberação na cidade e que, embora não tenha conseguido impedir a aprovação do projeto, conseguiu atrasar seu trâmite e, ao final, levou à instauraçáo de uma mesa de negociações com a prefeitura que obteve algumas concessôes mínimas ${ }^{3}$.

De qualquer modo, em um contexto de governos (municipal, estadual e federal) fortemente hostis aos sindicatos e movimentos sociais, com projeto neoliberal e de austeridade, as lideranças reconhecem um vetor recente de aproximação entre os sindicatos e movimentos, nos quais a campanha contra o "Sampaprev" foi um momento importante. Por outro lado, persistem dificuldades e eventuais desencontros nas campanhas entre movimento sindical e movimento popular. A greve dos trabalhadores do SAMU, em abril de 2019, é um exemplo de uma campanha derrotada em que, segundo um militante do movimento popular de saúde da região do Campo Limpo entrevistado, houve pouca disposição do Sindsep em incorporar o movimento popular de saúde:

A SAMU por exemplo: acabaram com as bases da SAMU [...] quando o funcionalismo público, ele não procura o apoio da população, às vezes, lutando sozinho... às vezes não: toda vez... eles vão pra derrota... [...] era pra ter sido uma coisa que tinha sido revertida, o fechamento das bases da SAMU [...] só que a organização deles lá, se levantou uma organização, eu lembro que eu participei de uma plenária [...] eu tinha me colocado à disposição pra poder fazer a discussão junto com a população pra gente lutar com eles... sabe, eles não deram muita bola... aí quando a água bateu no pescoço mesmo que eles vieram, era coisa de 48 horas, 96 horas, pra eles fecharem as bases, aí não deu pra reverter... mas é isso que eu to falando, tem que ter apoio da população... (Dirigente do Movimento Popular de Saúde do Campo Limpo, membro do conselho gestor do Hospital do Campo Limpo, 30/09/2020).

Segundo esse mesmo entrevistado, houve também outras ocasiôes em que os sindicatos de saúde mostraram pouca disposição na colaboração com o movimento popular de saúde. Entre meados de 2017 e o começo de 2018, na tentativa da então recém empossada gestão João Dória em extinguir as unidades da Assistência Médica Ambulatorial (AMA) da cidade, houve extensa campanha organizada pelos movimentos populares de saúde contra essa medida, difundindo-se a partir de alguns conselhos gestores, fazendo importantes atos locais a partir da articulação com associaçóes de moradores e lideranças religiosas progressistas, organizando comissóes locais de

\footnotetext{
3 "O governo assumiu o compromisso de não instituiçăo de contribuição previdenciária dos servidores, acima da estabelecida na lei, de $14 \%$. Isso é relevante porque, na proposta do Bolsonaro, esse valor pode ser de até $22 \%$, de acordo com indicação dos estados e municípios.

Em outro ponto, o acordo prevê que não haverá migração dos servidores e servidoras que ingressaram na carreira até a edição da Lei 17.020 para o regime complementar. O regime segue vinculado ao Instituto de Previdência Municipal (Iprem). Já os novos servidores não serão obrigados a entrar no regime complementar do Sampaprev. Seguem vinculados ao Iprem até o teto de R \$ 5.845, com desconto de 14\%. Para quem ultrapassar esse teto, é possível optar pelo regime complementar. A prefeitura ainda garantiu o pagamento das aposentadorias e pensóes, mesmo em caso de problemas na previdência, com o caixa do tesouro municipal.

Sobre os dias de greve, a prefeitura aceitou o pagamento dos dias descontados mediante reposição das horas. Tal pagamento será efetuado em até sete dias com crédito em conta, e não por folha suplementar.

Também ficou acordado um "abono emergencial" para servidores ativos em R \$ 200 no nível básico, o do agente de apoio, que ganha $R \$ 1.182$, e $R \$ 300$ para o agente de políticas públicas, que recebe $R \$ 1.382,50$. Também instala a mesa negocial para carreiras, a partir de abril, para negociaçáo salarial com as carreiras diversas" (ARCARY, 2019, online).
} 
acompanhamento junto com parlamentares progressistas e obtendo, a partir de ação do Ministério Público, uma reabertura das unidades de AMAs. No entanto, segundo o líder entrevistado do movimento popular de saúde do Campo Limpo e Jardim São Luís, houve pouca colaboração de sindicatos na campanha: sendo todos esses equipamentos de gestáo terceirizada, o Sindsep pouco interviu no processo, enquanto os vários sindicatos das respectivas categorias celetistas também não priorizaram estrategicamente construir essas mobilizaçóes junto aos usuários (embora o SIMESP tenha participado de audiências junto ao Ministério Público e contribuído com o levantamento de denúncias de médicos).

Inversamente, também o dirigente do Sindsep constatou as dificuldades de engajamento do movimento popular em determinadas pautas, como a campanha contra o desmantelamento da Covisa em agosto de 2020:

No desmantelamento da Covisa, a gente não conseguiu ter os movimentos sociais... você tem lideranças que vão lá trazer o apoio, mas cê não tem um movimento [...] a relação da Covisa com a população não é direta, a Covisa é uma vigilância em saúde [...] a gente teve três atos lá, teve representação de movimentos sociais, sim, parlamentares, assim por diante, dando o apoio contrário a esse desmonte, mas não é a mesma coisa... (Dirigente do Sindsep, 03/09/2020).

Outra derrota política do sindicato se refere à luta contra o PL 749, que tramitou em regime de urgência ao longo do primeiro semestre de 2020, foi sancionado em julho de 2020, e regulamentado em agosto. Esse projeto, que extinguiu diversas autarquias e fundaçóes, afetou o setor de saúde principalmente pela extinçáo da Autarquia Hospitalar Municipal (AHM), que, entre outras funçôes, administrava onze unidades hospitalares no município, e que passou a ter todas suas funçôes delegadas à Secretaria da Saúde - segundo o sindicato, a medida deve desorganizar a administração do setor e tem a intenção de acelerar um processo de terceirização das unidades de saúde. Não obstante, o sindicato não foi capaz de organizar mais do que atos simbólicos e uma campanha nas redes sociais e não conseguiu ter grande apoio de movimentos sociais, ainda que o Conselho Municipal de Saúde tenha se posicionado contra a extinção da AHM.

Mas no contexto da pandemia também há casos de campanhas bem-sucedidas através das quais o sindicato sensibilizou a população. Uma luta que se deu paralelamente em diversos hospitais é aquela em defesa da disponibilização adequada de EPIs, na qual a busca, por parte do sindicato e dos ativistas do movimento popular de saúde, pela comoção da população e dos grandes veículos midiáticos com a situação de risco e com as mortes de trabalhadores da "linha de frente" foi fundamental para obter resultados - sobretudo em ano eleitoral. O sindicato conta que além de intensa campanha nas redes sociais e "atos relâmpagos" para denunciar a falta de materiais, o sindicato conseguiu que representantes da grande mídia entrassem nos hospitais para filmar a falta de materiais, o que teve grande impacto. Além disso, a dirigente da pasta de saúde do sindicato exemplifica um criativo repertório utilizado para chamar a atenção da população e comovê-la perante a falta de EPIs:

Logo no início da pandemia nós orientamos os trabalhadores a uma ação que foi muito importante e muito efetiva. Não tinha máscara e tá lá o paciente pra ser atendido. O trabalhador perguntava pra gente: "o que a gente faz? A gente atende sem máscara?”. Não! A gente não atende sem máscara, e a gente também não deixa de atender o paciente. A gente pega um lençol e rasga e faz a máscara do lençol. [...] Você pega o recurso que tá ali, utiliza ele pra não deixar esse paciente sem 
assistência. [...] se você tá num corredor que tem muito paciente, você faz isso e dá um grito: "nós estamos rasgando o lençol para fazer máscara, porque nós estamos sem máscara, e nós precisamos atender você”. Então isso fazia com que tinha uma adesão, né, dos pacientes, ali, dos familiares [...] isso teve uma repercussão muito grande, fizemos muito vídeo... (Dirigente do Sindsep, 04/01/2021).

Outra campanha com destaque, conduzida em coalizão com o movimento popular, foi a luta em agosto contra a proposta de terceirização do Hospital do Campo Limpo, a primeira proposta de terceirização apresentada pela prefeitura após a aprovação da extinção da Autarquia Hospitalar Municipal (AHM). Esse hospital, então unidade da AHM, já vinha passando por acentuado processo de "sucateamento", e já vinha se conformando um movimento em sua defesa. Em outubro de 2019, segundo me contou uma liderança do movimento popular de saúde da regiáo, o movimento de usuários, sem articulação com sindicatos, organizou uma importante manifestação contra a precarização do hospital; em novembro, novas iniciativas foram feitas, e o Sindsep se incorporou, trazendo também a pauta da defesa da valorização das carreiras dos assistentes de gestão de políticas públicas e agentes de apoio, que estavam, nesse mesmo período, em greve.

Em agosto de 2020, logo após a aprovação do PL 749, o tema ganhou nova centralidade quando os funcionários do hospital receberam a notícia (às pressas e sem o cumprimento dos devidos ritos legais) da terceirização do Hospital do Campo Limpo para a

Organizaçáo Social (OS) Hospital Israelita Albert Einstein, a mesma que já administrava a Unidade de Pronto Atendimento (UPA) anexa ao hospital. A OS assumiria a maior parte do quadro de funcionários e a gestão dos setores hospitalares mais lucrativos.

Em íntima articulação com o movimento de usuários e o conselho gestor, o sindicato entrou com uma ação no Tribunal de Contas do Município (TCM) e no Ministério Público (MP), organizou plenárias e, junto ao movimento popular, organizou atos visando alertar a população e pressionar as instâncias institucionais. O sindicato incentivou também trabalhadores e pacientes a gravarem vídeos que foram divulgados nas redes sociais.

A prefeitura e a OS seguiram tentando impor o processo "a toque de caixa", e mesmo contra uma resistência inicial dos servidores em passar a gestão do hospital para a equipe da OS, esta conseguiu assumir praticamente todos os setores do hospital, com exceção do almoxarifado e da farmácia. No entanto, os servidores e a população seguiram organizando atos em frente ao pronto socorro e conseguiram, com parecer favorável ao movimento pelo Conselho Gestor da Unidade, pelo Conselho Municipal de Saúde e pelo TCM, reverter a terceirização. A OS abandonou o hospital, segundo a dirigente do Sindsep entrevistada, em situação de grande desorganização e irresponsabilidade com os pacientes.

Os entrevistados contam que, junto com a proposta de terceirização, a prefeitura disponibilizara para a OS recursos para reformas da fachada e de outros equipamentos do hospital, em uma ofensiva para associar a terceirizaçáo à melhoria do serviço prestado. Sendo a OS em questáo a mesma que administra o famoso hospital particular Albert Einstein no Morumbi, que atende a elite paulistana, a associação entre terceirização e piora no serviço não era natural para a população; mas, para realizar esse convencimento, os líderes do movimento popular ressaltaram o fato de que a UPA anexa ao hospital já era gerida pela OS, e que esta tinha um atendimento muito pior do que o do resto do hospital. Além disso, durante o breve período de implementação da gestão terceirizada no hospital, foram apurados muitos casos de maus tratamentos aos pacientes - segundo a dirigente entrevistada, o Einstein estaria provavelmente contratando os residentes de sua escola de medicina 
para fazer o atendimento, sem o acompanhamento necessário de trabalhadores mais experientes. Por fim, os líderes do movimento argumentavam também que as unidades da rede hospitalar de administração terceirizada eram, em geral, hospitais de "porta fechada", ao contrário daquelas de administração direta, como a do Campo Limpo.

Lideranças religiosas progressistas, o "Ponto de Cultura Casa dos Meninos" no Jardim São Luís, a Associação Nova União do Promorar, a Associação da Vila Prel, militantes partidários, lideranças parlamentares e movimentos como o Movimento dos Trabalhadores sem Teto (MTST, que tem ocupaçôes importantes na Zona Sul da cidade) foram importantes colaboradores militantes nesse movimento. O SIMESP também participou desse processo.

Por outro lado, o movimento contra a terceirização enfrentou oposição ativa de outros setores da sociedade civil na região, a exemplo do Sindicato dos Agentes Comunitários de Saúde, descrito por um entrevistado do movimento popular de saúde como um sindicato "pelego" e cujo dirigente depois se lançou como candidato. No mesmo sentido, outras associaçóes de moradores da regiáo são ligadas a vereadores da base da prefeitura, constituindo importantes máquinas políticas clientelistas locais e que obviamente náo apoiaram a mobilização contra a terceirização - ainda que uma dirigente sindical entrevistada conte que, em um evento local com a participação do prefeito e um influente vereador governista, o sindicato tenha ido fazer uma agitação da defesa do hospital e tenha conseguido angariar apoio entre moradores que assistiam ao evento.

A vitória contra o processo de terceirização do Hospital do Campo Limpo expressa que, embora os movimentos sindicais e populares não tenham sido capazes de organizar uma grande campanha municipal contra a PL 749 ou contra o "desmonte" da Covisa, houve casos de resistências locais bem-sucedidas à terceirização. Os entrevistados mostravam-se conscientes de que essa vitória não significava uma reversáo total da estratégia de terceirização da prefeitura, mas essa campanha foi descrita, pelos entrevistados, como uma luta muito importante e um "fôlego" em um contexto de muitas derrotas.

Por outro lado, reconhecem que a aliança entre os usuários e o sindicato, táo importante para essa vitória, não se repete em outras regióes da cidade:

Ali tem uma ligação viva, né, é constante... isso a gente tem dificuldade em outros hospitais... e o que ta acontecendo no Campo Limpo aconteceu nos outros, mas aí você tem uma dificuldade tanto de sindical, do trabalhador, quanto na ligação com o movimento... que nem: se você quiser depois acompanhar, semana que vem (...) a gente vai fazer no Hospital XXIII, ali na Mooca, no Tide Setúbal [em São Miguel Paulista], manifestaçôes contrárias a essas terceirizaçôes... mas não é o mesmo patamar que ocorreu no Campo Limpo... então pra nós hoje o Campo Limpo é um exemplo, de juntar o movimento social, popular, com o movimento sindical, que é a luta dos trabalhadores da unidade, que deu positivo (Dirigente do Sindsep, 03/09/2020).

Travamos conhecimento também com outros movimentos locais na cidade, em nossa entrevista com ativistas da Zona Norte e da Zona Oeste da cidade, que organizaram campanhas importantes durante a pandemia. Na regiáo da Brasilândia, uma das mais duramente atingidas nos primeiros meses da pandemia, a frente Brasilândia Pede Socorro (que teve como principal impulsionador o Diretório Zonal do PT da região) organizou iniciativas pela abertura integral do Hospital Municipal da Brasilândia, há muitos anos paralisado por obras e de inauguração apenas parcial recente, bem como organizou atos pela abertura de novas UBSs em regióes há muito desatendidas do distrito, como no Jardim Damasceno. Nesses movimentos, houve também adesão de sindicatos (sobretudo 
apoio de estrutura material e apoio de dirigentes), mas o ativista local que entrevistei destacou, sobretudo, a adesão de uma ampla rede de organizaçóes da Brasilândia que articulava, desde o começo da pandemia, açóes de assistência social na região (Rede Brasilândia Solidária), mas que não tinha grande histórico de atuação reivindicativa até então. Essa aproximação ajudou a dar peso para a campanha pela reabertura do Hospital da Brasilândia.

Ativistas da Frente Brasilândia Pede Socorro também compuseram, junto a militantes do movimento popular de saúde da Zona Oeste, sindicatos de saúde, militantes partidários, e também organizações como a rede de comunicação Observatório Vila Leopoldina, uma campanha pela reabertura integral do Hospital Sorocabana (na Lapa), pauta histórica e que, no contexto da pandemia, viu condiçôes para sua efetivação. Esse hospital, que seria importante para o atendimento da população da região Noroeste, também há muito tempo funciona em nível muito aquém de sua capacidade, sob pretexto de um imbróglio judicial entre estado e município.

Tanto no caso do Sorocabana quanto do Hospital da Brasilândia, a prefeitura foi alvo de críticas por direcionar muitas verbas à abertura de hospitais de campanha enquanto uma série de equipamentos públicos permanentes eram sub-utilizados. A partir de julho, esses movimentos conseguiram que a prefeitura não renovasse os contratos com as empresas dos hospitais de campanha e, em vez disso, abrisse novos leitos nos referidos hospitais municipais subutilizados. No caso do Sorocabana, houve intercessão pela abertura do Hospital não apenas por vereadores ligados à esquerda. No entanto, mais recentemente, com a soluçáo judicial do imbróglio quanto ao nível administrativo do hospital, um vereador do PTB envolvido nessa pauta aventa positivamente a possibilidade da reforma do hospital ser conduzida em Parceria Público-Privada - nesse último caso, o hospital seria administrado por uma Organização Social ${ }^{4}$, contra a proposta dos sindicatos.

\section{LUTAS EM COALIZÃO NA SAÚDE: DISCUSSÃO DOS RESULTADOS}

No setor de serviços públicos, incluindo os serviços de saúde, existem importantes particularidades favoráveis ao desenvolvimento de coalizóes. Os trabalhadores de serviços públicos, como os da saúde, são inerentemente enredados na vida comunitária, espacial e funcionalmente. A qualidade de suas condições de trabalho é, em muitos âmbitos, diretamente proporcional à qualidade do serviço que prestam. Não é de se espantar, portanto, que seja maior a ocorrência de casos de mútuo interesse entre movimento popular e movimento sindical nessas categorias, como argumenta Tattersall (2006).

Não obstante, gostaríamos de ressaltar que não se deve considerar que a relação direta dos trabalhadores de serviços públicos com a população implique em uma relação automática com seus movimentos. Medidas como a terceirização do Hospital do Campo Limpo, ou a subutilização dos hospitais Sorocabana e da Brasilândia, ou a falta UBSs, ou o fechamento de bases do SAMU, ou o fechamento de AMAs, ou o fechamento da Covisa, etc., não apenas impactam de forma diferenciada o segmento usuário e o segmento trabalhador, como os "interesses" não podem ser considerados como dados espontânea e inequivocamente, como se existissem sistemas dados de classificação e uma única racionalidade abstrata. A percepção dos "interesses" é ativa e processualmente construída ao longo das lutas sociais e mobilizaçóes. A atuação conjunta e profunda entre trabalhadores e a população, por exemplo, pode ajudar a gerar um conjunto de classificaçóes e discursos partilhados, e disposiçóes políticas análogas. 
O tema da terceirizaçáo é um bom exemplo a esse respeito: a perspectiva de que a terceirização gera piora no serviço certamente não é automática na população usuária. Mas a existência de tradiçóes de luta conjuntas pode ajudar a difundir, do movimento sindical para o movimento popular, as percepçóes de que as terceirizadas têm interesse apenas em lucrar com os contratos, portanto apenas diminuir os custos do serviço; de que podem coagir os funcionários a não denunciarem más condiçôes de serviço, na medida em que não há estabilidade empregatícia; etc.

As tradiçôes locais de luta que geram essas disposiçôes políticas partilhadas se expressam nos territórios. Assim, vimos como os dirigentes do Sindsep se referiam com preocupação às perspectivas de luta contra a terceirização em outras regiōes da cidade: porque ao contrário do Campo Limpo, essas regiôes não dispóem de um forte movimento popular de saúde ligado ao movimento sindical, conselhos gestores progressistas, etc. Constituem-se assim tradiçóes territorializadas de luta. A ideia de que há, nas diversas escalas espaciais que se examine, determinadas tradiçóes de luta, sedimentada nas estruturas organizativas de sindicatos e movimentos sociais, nas relaçóes mútuas entre eles e nos discursos que partilham (ou não partilham), é discutida com mais detalhes por Nowak (2019). Nossa pesquisa nos sugere que essas tradiçôes podem ser encontradas inclusive "abaixo" do nível "municipal", a partir das trajetórias singulares de lutas dos bairros.

Para cada território da cidade, seria interessante tarefa mapear a formação das tradiçôes locais de luta. No caso do Campo Limpo, por exemplo, a coordenadora de base da regiáo, que entrevistamos, apresenta que, quando assumiu essa tarefa no sindicato, já na segunda metade da década de 2010, sua antecessora já havia, há décadas, lutado para construir um movimento sindical articulado com movimentos sociais na região; além de militante sindical, essa dirigente fora do movimento eclesial de base da regiáo. Esse "coenvolvimento" de um mesmo ativista em diversos movimentos distintos parece ser um importante vetor de fortalecimento dos movimentos e de integração entre eles, e foi um tópico que apareceu, além desse, em outros momentos da pesquisa.

Se certamente uma tradição espacial específica de luta não pode ser atribuída à trajetória de uma única pessoa, por outro lado as trajetórias individuais de ativismo expressam as relaçóes (histórico-geograficamente específicas) estabelecidas entre, nos termos de Mathieu (2019), o "campo sindical" e o "espaço dos movimentos sociais". Ao mesmo tempo, embora a conformação de tradiçôes espaciais de luta tenha um efeito sobre as possibilidades de lutas futuras nesses territórios (ou seja, há um tipo de path-dependency), há sempre a possibilidade de aproveitar determinadas oportunidades políticas para criar novas relaçóes e alterar configuraçôes tradicionais - é o caso da forma como o movimento de saúde da Brasilândia conseguiu incorporar movimentos sem grande tradiçẫo reivindicativa prévia em suas mobilizaçôes em defesa da reabertura integral do hospital na região.

De qualquer modo, em geral, mesmo no interior do movimento de saúde e em se tratando de sindicatos cutistas (tradicionalmente críticos, portanto, a um estreito corporativismo sindical) segue havendo grandes desafios no que tange às coalizóes. A maioria das coalizões é ad hoc, com sindicatos dando apoio estrutural ou recebendo apoio militante dos movimentos. Mesmo em casos em que há impacto direto às comunidades, muitas vezes os sindicatos mostraram pouca disposição em incorporar o movimento popular aos espaços deliberativos, o que reduz a capacidade de engajamento destes. Um dirigente entrevistado afirmou que, em geral, a diretoria do sindicato determinava iniciativas e cabia aos diretores de base em cada caso avaliar se seria possível ampliar essas iniciativas com o apoio de movimentos locais, ou então apenas se somava "em apoio", geralmente de estrutura, a iniciativas convocadas independentemente pelo movimento popular; embora no caso do Campo Limpo, excepcionalmente, as deliberaçóes tenham sido conduzidas conjuntamente, através das reunióes do conselho gestor e de outras plenárias envolvendo tanto trabalhadores quanto usuários. 
Mas mesmo em importantes coalizôes de apoio mútuo - segundo tipologia de Tattersall 2006; 2013) -, com importante capacidade de mobilização e eventualmente de sucesso, como no caso do Hospital do Campo Limpo, segue havendo desafios do ponto de vista da continuidade e organicidade dessas coalizóes. Por exemplo: muitos dos fóruns permanentes do movimento popular, fundamentais para circular pautas, expertises e experiências de ativismo não contam com participação orgânica de sindicatos. É o caso, mencionado por um dos entrevistados, do "Fórum do Fundão" da M’boi Mirim, que congrega diversos movimentos (de moradia e regularização fundiária, de saúde, de cultura, de meio ambiente, educação, de esporte) que atuavam na região, de modo que, mesmo mantendo cada um suas próprias "especialidades", pudessem se apoiar mutuamente e potencializar as lutas locais. Tal frente de atuaçáo conseguiu diversos avanços sociais na comunidade referida.

Um dos dirigentes entrevistados mencionou que uma atuação excessivamente orientada para os movimentos sociais poderia ter como resultado insatisfaçóes na base, que possui tendências corporativistas e que, portanto, é necessário equilibrar a orientação societal mais ampla com as pautas específicas. Ao mesmo tempo, os dirigentes entrevistados caracterizam a existência de uma tendência de aproximação entre sindicatos e movimentos na atual conjuntura. Em parte, reconhecem essa tendência como relacionada ao esvaziamento dos espaços institucionais participativos, que permitiam que cada movimento pudesse apresentar e viabilizar, separadamente, suas demandas perante as autoridades. Segundo os entrevistados, antes da atual gestão, ainda que ocorressem mobilizaçóes, havia maior equilíbrio entre a mobilização, por um lado, e advocacy em espaços institucionais, por outro. Um dos dirigentes do Sindsep entrevistados ressalta, por exemplo, que embora o governo Haddad (2013-2016, PT) tivesse também avançado na terceirização de muitas unidades de saúde, ele mais facilmente se dispunha a recuar em casos em que o movimento de saúde local se expressasse e mobilizasse contrariamente, ainda que náo fossem mobilizaçóes necessariamente "de massas".

Frente à atual intransigência do Poder Executivo, cada vez mais ganha prioridade no repertório de estratégias institucionais dos sindicatos e movimentos sociais de saúde também o apoio de parlamentares progressistas e mesmo recursos a agências jurídicas como o MP e o TCM, o que já se exprime em alguns dos casos mencionados. Mas a possibilidade desses recursos funcionarem se relaciona também à possibilidade do movimento com eficácia chamar a atenção da população e das autoridades locais à situação que se denuncia, de modo que formas de mobilização devem ganhar importância, em particular campanhas em coalizão. Essas mudanças estratégicas podem ser descritas, nos termos de Milkman (2015), como um ganho de importância do outside game com relação ao inside game (duas das facetas essenciais e distintivas da atuação dos sindicatos enquanto players estabelecidos), devido a uma crise de espaços institucionais de participação do sindicalismo.

Em um contexto de pandemia e isolamento social, os dirigentes entrevistados ressaltam que os atos convocados não tinham como principal objetivo se massificar, mas conseguir chamar a atenção e conversar com a população em um contexto em que enorme parcela desta não teve condiçóes necessárias para cumprir o isolamento social. A dirigente da pasta de saúde do Sindsep define esses atos como "relâmpagos" e descreve um cuidado permanente por parte de todos os trabalhadores envolvidos nesses atos em deixar claro à populaçáo que não se tratava de greves ou transtornos com fins corporativistas e que os trabalhadores querem atender a população adequadamente.

A pandemia impactou também outros repertórios de ação coletiva. Segundo ativistas com quem conversei, o movimento deixou, nos primeiros meses de pandemia, de usar cartas abertas e panfletos. Pude ver, nas redes sociais, novos repertórios criativos usados para abordar a população em alguns momentos, como a distribuição de máscaras. A atuação nas redes sociais teve também grande importância, por exemplo, via divulgaçóes das iniciativas em grupos de bairro no Facebook, ou a 
divulgação de vídeos de trabalhadores e usuários acerca do hospital que tiveram boa repercussão nas redes sociais na campanha do Hospital do Campo Limpo e outras campanhas pela disponibilização de EPIs.

A respeito da persistente política de terceirização da rede hospitalar pela gestão municipal, é importante observar uma atualizaçáo quanto ao caso do Hospital do Campo Limpo. Em janeiro de 2021, ainda em meio à pandemia, a prefeitura anunciou a demissão de dezenas de trabalhadores desse hospital que haviam anos antes sido contratados em regime de emergência e cujos contratos há muito tempo haviam expirado. A dirigente do Sindsep com quem voltamos a conversar após o ocorrido argumentou que o sindicato não teria condiçóes de lutar pelo emprego desses trabalhadores, devido à situaçáo de irregularidade dos contratos, mas buscaria garantir que eles tivessem acesso a todos seus direitos de seguridade. Frente a essa situação: a demanda do sindicato, para além de uma reposição rápida da força de trabalho de modo a evitar a sobrecarga dos funcionários e a piora do serviço, é a substituição desses trabalhadores por concursados; mas a dirigente afirma que "temos consciência de que a conjuntura não favorece concurso". A proposta da prefeitura, segundo caracteriza o sindicato, é a substituição desses funcionários por trabalhadores terceirizados, em um novo convênio com a Organização Social Centro de Estudos e Pesquisas "Dr. João Amorim” (CEJAM), que já é responsável pela contratação de uma parte dos funcionários auxiliares do hospital. Isso pode confirmar a hipótese, já aventada pela dirigente em entrevista realizada em setembro/2020, que frente ao revés na tentativa de terceirização da gestão do hospital a Prefeitura tentaria avançar com a terceirização de forma gradual, subcontratando os funcionários de determinadas alas hospitalares, etc. Essa realidade ressalta o caráter "parcial" das vitórias do movimento de saúde em um contexto hostil à ação coletiva.

\section{CONCLUSÃO}

Para analisar as estratégias de coalizão do movimento de saúde, foi necessário analisar brevemente o contexto político-institucional em que a crise pandêmica impactou o sistema de saúde da cidade de São Paulo. Embora dispondo de uma importante rede de espaços institucionais de participaçáo, o movimento sindical de saúde e os movimentos populares de saúde dos distritos da cidade se encontram perante uma gestão municipal pouco permeável à sociedade civil e com projetos sistemáticos de subcontratação de unidades de saúde e desvalorização do quadro de servidores. $\mathrm{Na}$ pandemia, esses projetos não foram alterados: para além da extinção da Autarquia Hospitalar Municipal e tentativa de terceirização do Hospital do Campo Limpo, houve o processo de "desmonte" da Covisa e sindicatos relataram insuficiência no fornecimento de EPIs.

Esses projetos, que se expressaram com particular agudeza na pandemia, já vinham sendo aplicados há alguns anos e impactam não apenas a qualidade do serviço e das condiçóes de trabalho, mas também a organização sindical, sobretudo reduzindo a circunscrição oficial de sindicatos de servidores públicos e aumentando a vulnerabilidade dos trabalhadores desse setor a demissôes e à coerção patronal. Para fazer frente a esses processos, sindicatos como o Sindsep já vinham recorrendo a estratégias de coalizão, mesmo que frequentemente com limites no que se refere à profundidade e permanência dessas coalizóes. No contexto pandêmico, essas campanhas em coalizão puderam se aproveitar também da maior comoção social-midiática para aumentar sua adesão e reverberação, o que pode ser descrito como o uso estratégico de "oportunidades políticas" para a mobilização (MCADAM, TARROW, TILLY, 2001). Trata-se, em primeiro lugar, de comoçôes entre os próprios trabalhadores, que em muitos casos impeliu-os à mobilização, como o falecimento de colegas por Covid-19. Além disso, trata-se da comoção da população em geral, à qual apelaram os movimentos 
para avançar em demandas históricas dos movimentos populares de saúde dos territórios, como pela reabertura integral dos hospitais Sorocabana e da Brasilândia, ou na luta contra a terceirização do Hospital do Campo Limpo, ou nas campanhas pela disponibilização de EPIs, que obtiveram alguns resultados favoráveis. Essa "mobilização da comoção" deve ter se beneficiado ainda da proximidade do ano eleitoral para mais eficazmente sensibilizar atores institucionais. Além disso, ao contrário das remoçốes da Covisa e do PL 749, que exigiam um grande enfrentamento de abrangência municipal, essas iniciativas territoriais puderam se valer de determinadas tradiçóes locais de luta como a da região do Campo Limpo, ou se ampliar pela incorporaçáo de frentes locais sem grande trajetória reivindicativa prévia, como a Rede Brasilândia Solidária, em um bairro de forte comoção por ser entáo um dos mais atingidos pela pandemia.

Apelos ao Ministério Público e ao Tribunal de Contas do Município foram importantes, tal como o apoio de alguns parlamentares e de movimentos sociais não diretamente ligados à pauta da saúde (movimentos de moradia, associaçôes de moradores, etc.). Em todos os casos, ainda, chamar a atençâo da grande mídia foi fundamental para os resultados alcançados, e um elemento consciente das estratégias adotadas. Importante, ainda, foram o compartilhamento de conteúdos nas redes sociais e a realizaçáo de pequenos protestos, "atos-relâmpago" e outras performances. Essas estratégias e repertórios reforçam o fato de que a ação sindical não se restringe necessariamente a greves (sobretudo em um contexto pandêmico em que, ademais, qualquer tentativa de greve do setor de saúde geraria imenso desgaste com a opiniáo pública), podendo aproximar-se em alguns casos dos repertórios de ação tipicamente associados aos movimentos sociais (TILLY, 2010).

Entre os casos analisados durante a pandemia, importa ressaltar que há aqueles envolvendo pautas "defensivas" (como contra a terceirização do Hospital do Campo Limpo), casos envolvendo pautas "propositivas" (como a luta pela abertura integral de hospitais) e casos ao mesmo tempo defensivos e propositivos (como a luta pelo oferecimento de mais equipamentos de proteçáo individual). Em todo caso, não podem ser analisados em separado do contexto de políticas públicas de saúde da atual gestáo municipal.

Por fim, gostaríamos de mencionar duas linhas de pesquisa que podem trazer úteis complementos aos resultados aqui expostos: primeiramente, a comparação entre as formas de mobilização e organização dos servidores das unidades de administraçáo direta, como os representados pelo Sindsep, com aquela dos trabalhadores de unidades de saúde subcontratadas, mais vulneráveis. Em segundo lugar, a comparação das mobilizaçôes de servidores de saúde com trabalhadores de outros ramos do serviço público também duramente impactados pela pandemia, como o setor educacional.

\section{REFERÊNCIAS BIBLIOGRÁFICAS}

ARCARY, Gabriel. Greve dos Servidores em São Paulo Chega ao Fim Com Acordo e Assembleia Dividida, Rede Brasil Atual. Disponível em: <https://www.redebrasilatual.com.br/trabalho/2019/03/greve-dos-servidores-em-sao-paulo-chega-ao-fim-com-acordo-e-assembleia-dividida/>/. Publicado em: 8 mar. 2019. Acesso em: 13 mar. 2021)

BRAGA, Ruy. A rebeldia do precariado: trabalho e neoliberalismo no Sul Global. São Paulo/SP: Boitempo Editorial, 2017.

BREMAN, Jan; HARRIS, Kevan; LEE, Ching Kwan; LINDEN, Marcel van der. The Social Question All Over Again. In: BREMAN, Jan; HARRIS, Kevan; LEE, Ching Kwan; LINDEN, Marcel van der. The Social Question in the Twenty-First Century, California University Press, 2019, pp. 1-22. 
BOURDIEU, Pierre. Compreender. In: BOURDIEU, Pierre (org.). A miséria do mundo. Petrópolis/RJ: Editora Vozes, pp. 693-732, 2001 [1993].

COELHO, Rony. A participação institucional em São Paulo: Trajetória e a experiência no governo Haddad (PT, 2013-16). Revista Brasileira de Ciência Política, [s.l.], n. 31, p. 257-300, 2020.

FREGE, Carola; HEERY, Edmund; TURNER, Lowell. The New Solidarity? Trade Union CoalitionBuilding in Five Countries. In: FREGE, Carola; KELLY, John (eds.). Varieties of Unionism: Strategies for Union Revitalization in a Globalizing Economy. Oxford: Oxford University Press. 2004.

FREGE, Carola; KELLY, John. Union Revitalization Strategies in Comparative Perspective. European Journal of Industrial Relations, [s.l.], vol. 9, n. 1, p. 7-24, 2003.

GOMES, Rodrigo. "Saúde em SP não melhora com Covas, que cortou verba e desmontou serviços públicos”. Rede Brasil Atual. Disponível em: https://www.redebrasilatual.com.br/politica/2020/10/balanco-governo-covas-saude/. Publicado em: 27 out. 2020. Acesso em: 13 mar. 2021.

IBSEN, Christian Lyhne; TAPIA, Maite. Trade union revitalisation: Where are we now? Where to next? Journal of Industrial Relations, [s.l.], vol. 59, n. 2, p. 170-191, 2017.

MATHIEU, Lilian. The space of social movements. Social movement studies, [s.l.], vol. 20,n. 2, p. 1-15, 2019.

MCADAM, Doug; TARROW, Sidney; TILLY, Charles. Dynamics of contention. Cambridge: Cambridge University Press, 2001.

MCALEVEY, Jane. No Shortcuts: Organizing for Power in the New Gilded Age. Oxford: Oxford University Press, 2016.

MILKMAN, Ruth. The Double Game of Unions and the Labor Movement. In: DUYVENDAK, Jan Willem; JASPER, James M. Players and arenas: The interactive dynamics of protest. Amsterdam: Amsterdam University Press, 2015.

NOWAK, Jorg. Mass Strikes and Social Movements in Brazil and India: Popular Mobilization in the Long Depression. London: Palgrave Macmillan. 2019.

OBSERVATÓRIO LEOPOLDINA. Podcast - Obs. Disponível em: <https://soundcloud.com/ user-632735597-165569564/podcast-obs-27nov2020?fbclid=IwAR1RlGQFq-Sv1yge4lWjnTGyFWx8rvIO6HnFZ67Dzjoa0kkNhBQyQB7qvTc>. Publicado em: 27 nov. 2020. Acesso em: 13 mar. 2021.

TATTERSALL, Amanda. Bringing the community in: possibilities for public sector union success through community unionism. International Journal of Human Resources Development and Management, [s.l.], vol. 6, n. 2-4, p. 186-199, 2006.

. There Is Power in Coalition: A framework for assessing how and when union-community coalitions are effective and enhance union power. Labour \& Industry, [s.l.], vol. 16, n. 2, p. 97-112, 2013.

TILLY, Charles. Movimentos sociais como política. Brasília: Revista Brasileira de Ciência Política, [s.l.], n. 3, p. 133-160, 2010. 